\title{
ESTUDO DO DESEMPENHO TÉRMICO DE CÉLULAS- TESTE ENTERRADA E SEMIENTERRADA
}

\section{STUDY OF THE THERMAL PERFORMANCE OF BURIED AND SEMI- BURIED TEST CELLS}

\author{
Juliana Aparecida Biasi ${ }^{1}$ \\ Universidade do Oeste de Santa Catarina, Videira, SC, Brasil, juliana.biasi@unoesc.edu.br \\ Eduardo Leite Krüger ${ }^{2}$ \\ Universidade Tecnológica Federal do Paraná, Curitiba, PR, Brasil, ekruger@utfpr.edu.br
}

\begin{abstract}
Resumo
Uma alternativa construtiva vernacular dos grupos indígenas na região sul do Brasil baseava-se no enterramento da edificação com o provimento de cobertura leve. O presente estudo tem por objetivo avaliar o desempenho térmico de células-teste enterradas e semienterradas quando comparadas a uma célula controle térrea visando uma arquitetura bioclimática que utilize métodos passivos. O método é baseado na comparação das variações de temperatura medida no interior de células-teste quanto à temperatura externa e do solo medidos em Curitiba, PR, durante o período de inverno. As células testes foram confeccionadas em escala reduzida, todas com as mesmas dimensões e especificações de materiais. Para a avaliação de desempenho foram analisados a amplitude térmica, o atraso térmico, as diferenças de temperaturas e amplitudes de sensores superficiais e os índices de conforto de cada célula-teste. A análise de dados constatou que a célula-teste enterrada apresentou menor amplitude térmica e maior atraso térmico. No que tange à somatória dos graus-hora fora da faixa de temperatura de conforto, a célula-teste enterrada obteve o menor tempo em desconforto durante o período de inverno. Foi possível verificar também que quanto maior a área em contato com o solo, melhores as condições de conforto observadas.
\end{abstract}

Palavras-chave: Inércia térmica. Construção subterrânea. Construção enterrada.

\begin{abstract}
A vernacular housing alternative widely used by indigenous groups in southern Brazil is based on burying the more significant part of the dwellings and covering it with a vegetated roof. The present study aims to verify the thermal performance of buried and semiburied test cells when compared to a ground control cell as a bioclimatic strategy. The method is based on the comparison of temperature variations measured inside test cells concerning external and soil temperature measured in Curitiba, PR, during the winter period. The test cells were made on a reduced scale, all with the same dimensions and material specifications. The performance of each test cell was evaluated through the analysis of thermal fluctuations, time lag, differences in temperature, and amplitudes of surface sensors and comfort levels. Data analysis revealed that the buried test cell presented lower thermal amplitude and longer time lag. Regarding the sum of degrees-hours outside the comfort temperature range, the buried test cell obtained the best performance during the winter period. It was also possible to verify that a greater surface area in contact with the soil increases the thermal performance.
\end{abstract}

Keywords: Thermal inertia; Underground construction; Buried construction.

How to cite this article:

BIASI, J. A.; KRÜGER, E. L. Estudo do desempenho térmico de células-teste enterrada e semienterrada. PARC Pesquisa em Arquitetura e Construção, v. 10, p. e019023, 30 maio 2019. DOI: https://doi.org/10.20396/parc.v10i0.8653908 


\section{Introdução}

"Casas protegidas pela terra foram desenvolvidas principalmente para abrigo, calor e segurança para os primeiros habitantes humanos" (ANSELM, 2012, p. 126). Construções subterrâneas, ou mesmo parcialmente abrigadas no subsolo, são uma das formas de construção mais antigas utilizadas pela civilização humana. As cavernas são abrigos de formação natural que serviram de moradia transitória à espécie humana há milhares de anos, exemplificadamente nos vestígios nas cavernas de Altamira, na Espanha e Lascoux, na França, entre tantas outras distribuídas no globo terrestre. Além disso, nas eras glaciais, as cavernas proviam um abrigo eficaz contra as intempéries.

Em sua revisão sobre edifícios subterrâneos para o desenvolvimento de eficiência térmica e desenvolvimento sustentável, Alkaff et al. (2016) elencam edificações subterrâneas ao redor do mundo que foram construídas ao longo da história arquitetônica da humanidade: na Jordânia, localizada em uma área desértica, quente e árida, está a cidade histórica de Petra, construída no século 6 a. C. para abrigar dezenas de túmulos e outras estruturas e locais esculpidos ou construídos dentro da estrutura de pedra; na Capadócia, Turquia, durante o século 7 d.C. para que pudessem se esconder do Império Romano, os cristãos construíram uma cidade subterrânea em vários níveis com capacidade de abrigar mais de 50.000 pessoas; localizada em clima quente e árido, no nordeste do Irã, nas encostas da montanha de Sahand, está uma das estruturas subterrâneas mais conhecidas, formada por rocha vulcânica e que servia de moradia há mais de 700 anos; na Escócia encontra-se outra estrutura subterrânea famosa, chamada de Edinburgh Vaults, construída em arcos no ano de 1788 para abrigar tabernas, sapatarias e espaço de estocagem para produtos ilegais, sendo utilizada pelos menos abastados como residência em 1820.

No Brasil, as habitações subterrâneas têm ocorrência desde o sul de Minas Gerais até a serra gaúcha (WEIMER, 2005). São denominadas "buracos-de-bugre", conforme a terminologia da população local em pesquisa realizada por Chmyz et al. (2003) na cidade de Mandirituba, a menos de $45 \mathrm{~km}$ da capital, Curitiba, PR. "Buracos-de-bugre" consistem em uma escavação do solo para a formação do corpo do edifício e uma cobertura feita com matéria orgânica. São similares a outras moradias subterrâneas encontradas em Hokkaido, no Japão, e Sacalina, na Rússia (WEIMER, 2008). A principal justificativa para a presença de tais edificações vernáculas nestas regiões brasileiras é a de que os indígenas as utilizavam a fim de amenizar o intenso frio do inverno.

Existem três grandes grupos das tipologias de construções subterrâneas segundo a literatura acerca do tema (ALKAFF et al., 2016; ANSELM, 2012; HAIT, 2013). São elas:

a) Enterrada ou enterrada com átrio: usualmente se encontra completamente enterrada no solo, mas pode ter seu teto coberto ou não pelo solo, assim como pode ou não possuir átrio;

b) Com elevação exposta (semienterrada): é mais frequente em regiões montanhosas, pois a edificação subterrânea fica inserida nas escarpas, aproveitando a topografia local;

c) Artificialmente coberta com terra (semienterrada): a terra é colocada em cima da estrutura da edificação previamente projetada e construída para este propósito.

Staniec e Nowak (2011) e Benardos et al. (2014) abordam os benefícios das construções que utilizam o solo como parte integrante de seu invólucro, tais como a melhora na qualidade acústica, redução da poluição visual, menor exposição às condições climáticas 
que degradam as fachadas, com, consequentemente, menor necessidade de manutenção.

O solo pode ser considerado um grande reservatório de energia. Sua capacidade de armazenar calor é tão eficiente que as variações de temperatura superficial diurnas do solo se amenizam com a profundidade, muitas vezes eliminando variações sazonais, em função do clima local e da constituição, tipo e cobertura do solo. Assim, em muitos casos, a temperatura do solo permanece constante a partir de determinada profundidade (DERRADJI; AICHE, 2014). Isso ocorre devido à inércia térmica, que é a capacidade do solo ou de uma edificação de armazenar e liberar calor. O efeito é conseguido através do acúmulo de calor em seus elementos construtivos constituintes. O uso da inércia térmica na edificação aumenta o efeito de atraso térmico e atua na diminuição da amplitude da temperatura interior em relação à exterior, evitando os picos (LAMBERTS; DUTRA; PEREIRA, 2014).

Givoni (1991) argumenta que, em regiões com clima temperado, com invernos frios e verões moderados, o solo pode ser utilizado para gerar resfriamento passivo, pois a temperatura do solo a uma profundidade de 2 a $3 \mathrm{~m}$ será baixa o suficiente para servir como fonte de resfriamento.

A pesquisa de Alves e Schmid (2015), realizada para diversas regiões bioclimáticas brasileiras - dentre estas a cidade de Curitiba, abordou modelos matemáticos e considerou para tanto as profundidades de $0,5 \mathrm{~m}$ - uma profundidade que apresenta variação sensível de temperatura, oscilando com as estações ao longo do ano - e de 4,0 $\mathrm{m}$ - profundidade que quase não apresenta variações térmicas durante o ano. Os resultados da pesquisa mostram que o ideal seria a utilização de uma superfície com maior absorção solar e com uma maior profundidade para que as necessidades de resfriamento e aquecimento possam atender às demandas sem a utilização de meios ativos para a obtenção de conforto.

Na revisão bibliográfica publicada por Alkaff et al. (2016) é possível verificar as diversas pesquisas e publicações realizadas acerca do assunto, que podem ser divididas nos seguintes grupos: estudos realizados com medições, estudos matemáticos e estudos realizados com simulação computacional, sejam para edificações vernáculas ou não.

Para o presente estudo, realizou-se um levantamento, nas plataformas Scopus e INFOHAB, da produção científica desenvolvida no decorrer dos anos de 1983 a 2018 sobre construções enterradas e sua abordagem ao desempenho térmico. Este levantamento mostrou resultados com as mesmas linhas e métodos utilizados nas diversas pesquisas apontadas por Alkaff et al. (2016). Como forte justificativa para o presente estudo, não foram identificados estudos que utilizaram células-teste para realizar a comparação dos resultados no que diz respeito a edificações enterradas ou semienterradas e seu desempenho térmico.

O objetivo deste estudo é verificar o desempenho térmico proporcionado pela inércia do solo em células-teste enterradas e semienterradas comparativamente a uma célula controle térrea, durante o período de inverno para Curitiba - Paraná.

\section{Método}

A natureza do estudo é quase-experimental, pois as células-teste (CTs) estiveram expostas a fatores não controlados como o clima e intempéries. Conforme Gil (2010), nos casos de uma pesquisa quase-experimental, não se tem o rigor e o pleno controle de estímulos experimentais ou a distribuição aleatória dos elementos que compõem os grupos. O importante nestes casos é que o pesquisador apresente seus resultados esclarecendo o que seu estudo deixou de controlar (GIL, 2010). O experimento utiliza o 
método comparativo, analisando as CTs enterrada e semienterrada em relação a uma célula controle térrea, à temperatura ambiente externa e à temperatura do solo medidas durante o mesmo período.

Os procedimentos utilizados no experimento baseiam-se em trabalhos já realizados na temática: uso de células-teste e célula controle confeccionadas com os mesmos materiais e dimensões como variável comum; o tratamento singular de cada célula quanto ao uso ou não de técnica passiva como variável manipulada para diferenciação; e o monitoramento da temperatura interna e superficial utilizando dataloggers para a coleta e análise de resultados comparativos (FERNANDES; KRÜGER, 2017; KRÜGER et al., 2016).

\section{Células-teste}

Para o desenvolvimento deste estudo, foi reutilizada uma das células do experimento realizado por Krüger et al. (2016) a fim de manter a mesma tipologia, a qual já havia sido adotada em ensaios anteriores. A Figura 1 apresenta as medidas padronizadas do módulo utilizado para esta pesquisa.

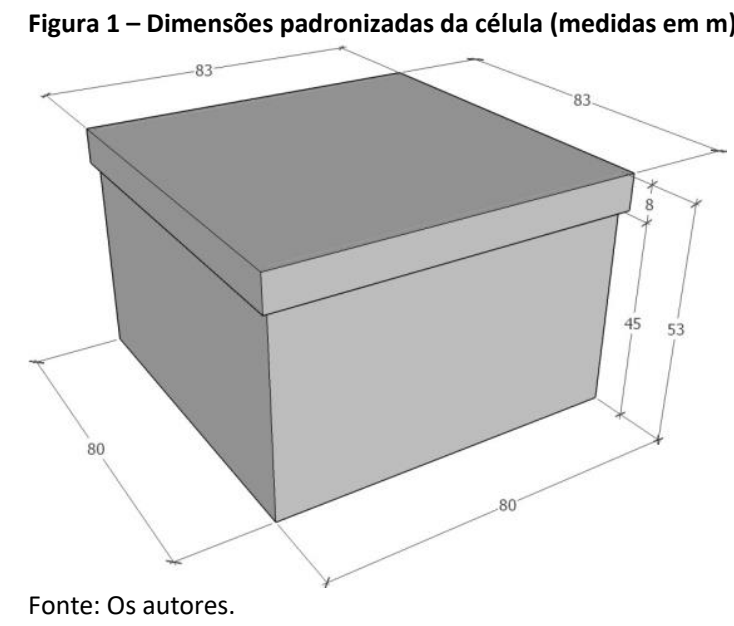

Posteriormente, também foram confeccionados dois módulos com as mesmas dimensões e materiais (KRÜGER et al., 2016, p.109):

Utilizou-se compensado naval com $15 \mathrm{~mm}$ de espessura. Para resistir melhor às intempéries ambos receberam como base uma camada de verniz marítimo. Posteriormente, ambos foram pintados com acrílico esmaltado na cor branca. Internamente, as paredes e os pisos foram revestidos com uma camada de $4,5 \mathrm{~cm}$ de poliestireno expandido - EPS.

Após receberem a pintura, foram aplicadas três demãos de stain impregnante premium na cor transparente, a fim de conferir aos três módulos maior resistência à umidade e a fungos.

A transmitância térmica dos módulos desenvolvidos era de $\mathrm{U}=0,707 \mathrm{~W} /\left(\mathrm{m}^{2} . \mathrm{K}\right)$ e a capacidade térmica era de $\mathrm{CT}=18,528 \mathrm{~kJ} /\left(\mathrm{m}^{2} . \mathrm{K}\right)$, calculadas conforme procedimento descrito na NBR 15220 (ABNT, 2005).

Posteriormente, os módulos foram configurados distintamente quanto ao contato das suas paredes com o solo para utilizar a estratégia de ganho de massa térmica, diferenciando-se assim entre células-teste (semienterrada e enterrada) e célula controle (térrea), conforme a Figura 2. 


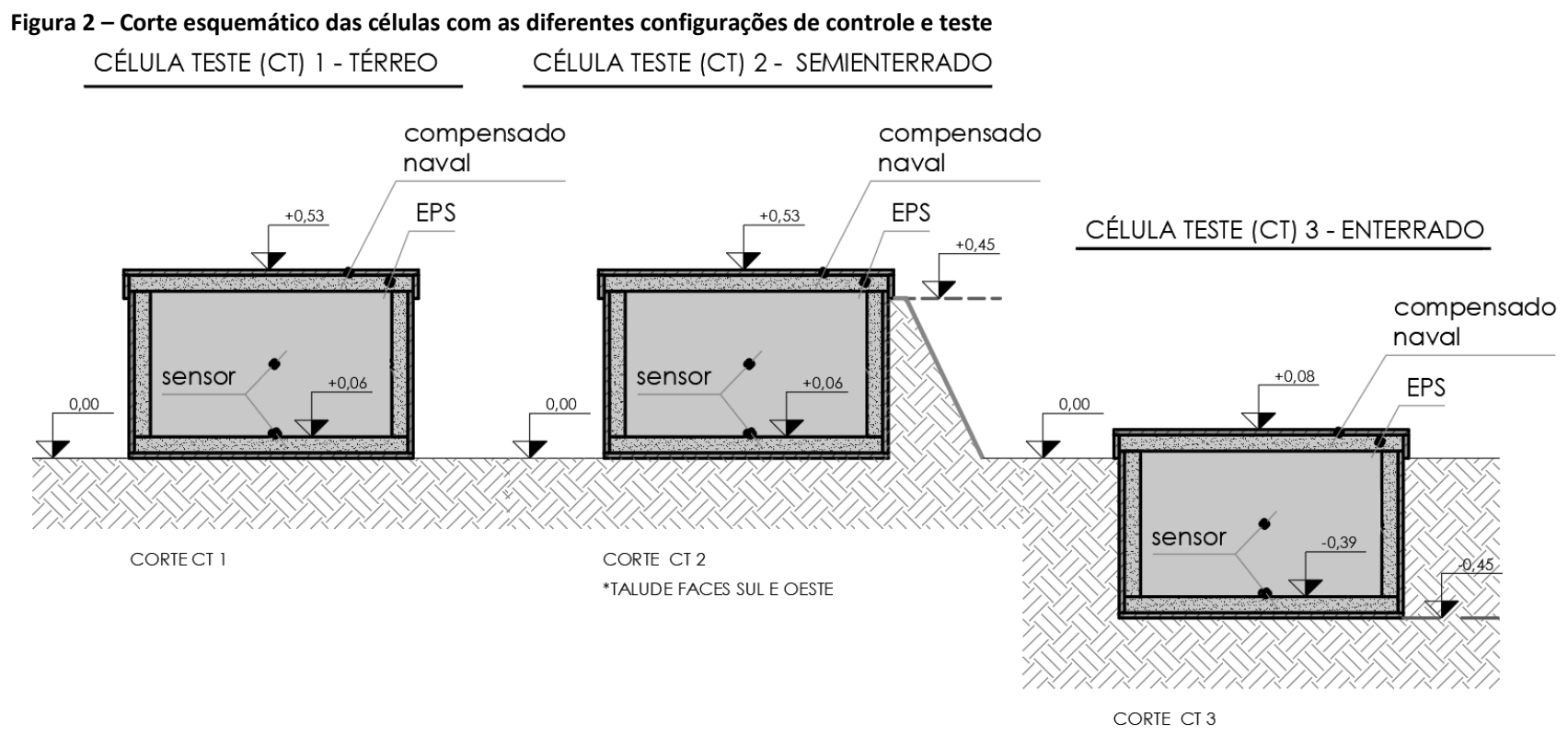

Fonte: Os autores.

A célula controle (CC) - térrea - possui todas as paredes livres, em contato com o ar. A célula-teste 1 ( $C T 1$ ) - semienterrada - no mesmo nível da CC, tem as faces sul e oeste cobertas por um talude de terra, sendo este último coberto por uma tela de mosquiteiro de cor verde o que o preveniu de erosões e desmoronamentos. Essas faces foram selecionadas com a intenção de aumentar a massa térmica da envoltória, porém com objetivos distintos: na face sul, como elemento de regulação de perdas térmicas, a qual é exposta a menor insolação e maiores perdas de energia no inverno, e na face oeste, como elemento de controle de ganhos térmicos, exposta ao maior pico de radiação solar diária quando as temperaturas externas estão mais elevadas. $O$ acréscimo da camada de terra à envoltória da célula aumenta a massa térmica do conjunto e permite a transmissão mais gradual do calor armazenado durante o período diurno para o ambiente interno em períodos noturnos, quando as temperaturas externas são mais baixas. A célula-teste 2 ( $\left.\mathrm{CT}_{2}\right)$ - enterrada - está abaixo do nível de $\mathrm{CC}$ e $\mathrm{CT} 1$, possuindo todas as suas paredes em contato com o solo local. Para conferir melhorias à impermeabilidade e resistência das células, todas as faces que estiveram em contato com o solo foram revestidas com lona transparente dupla, com 200 micra cada camada, posteriormente fixadas com grampos.

Os sensores de temperatura (dataloggers) foram posicionados centralizados sobre o piso e no centro do volume de ar de cada célula utilizada. Sensores de temperatura 'TagTemp NFC' foram utilizados para medição de temperaturas superficiais, no centro do piso. A temperatura do ar foi auferida por um registrador eletrônico modelo LogBox RHT. Externamente, instalou-se uma estação meteorológica (Hobo Weather Station), marca Onset Computer Corporation, modelo H21-001, para obtenção de dados de temperatura e umidade relativa locais. Também foram coletados dados de temperatura do solo obtidos através de um sensor do tipo PT10o acoplado junto à estação meteorológica. A ponta do sensor enterrado no solo foi posicionada a $50 \mathrm{~cm}$ de profundidade da superfície. O intervalo de registros foi de 5 minutos.

Observe-se que, anteriormente às medições, foi feita a padronização dos sensores, verificando-se os desvios a partir da média de valores obtida com exposição uniforme do grupo de sensores usados. Correções de sensores, quando necessárias, foram efetuadas a partir de equação de regressão linear. 


\section{Clima de Curitiba}

Curitiba está situada na região sul do Brasil, possui altitude média de $917 \mathrm{~m}$, seu clima é subtropical, mesotérmico, controlado por massas de ar polares e tropicais. A temperatura média anual é de $16^{\circ} \mathrm{C}$, apresentando grande amplitude térmica diária e sazonal. As chuvas são bem distribuídas ao longo do ano, com maior concentração no verão. O clima é classificado como Cfb (KOTTEK et al., 2006), com frio intenso no inverno e clima ameno no restante do ano. Fevereiro é o mês mais quente do ano, com média de temperatura de $22^{\circ} \mathrm{C}$ e máxima de até $35^{\circ} \mathrm{C}$, enquanto junho é em geral o mês mais frio do ano com temperatura média de $18{ }^{\circ} \mathrm{C}$ e mínima de até $-5^{\circ} \mathrm{C}$ (ROSSI; KRUGER; BRODE, 2012).

As estratégias de condicionamento térmico passivo para a zona bioclimática 1, onde está situada a cidade de Curitiba, sugerem o aquecimento solar da edificação e o uso de vedações internas pesadas a fim de garantir maior inércia térmica durante os meses de inverno. A norma NBR 15220 (ABNT,2005) ainda prevê que a utilização de condicionamento passivo durante o período mais frio do ano será insuficiente para garantir o conforto térmico, sendo listada como estratégia necessária a utilização de aquecimento artificial com calefação.

\section{Período de experimentação}

O experimento foi realizado durante o período de 30/06/2017 (0:00 h) até 09/07/2017 (23:55 h), contando com um total de 10 dias. Observando a NBR 15220 (ABNT,2005), que diz que, para a zona bioclimática 1, o condicionamento passivo será insuficiente durante o período mais frio do ano para manter o conforto térmico do ambiente interno, e também levando-se em conta os resultados do estudo de Alves e Schmid (2015), que indicam que a cidade de Curitiba apresenta uma maior demanda energética no período do inverno para aquecimento, conclui-se que o problema concentra-se nos meses mais frios do ano, o que justifica a escolha da estação de inverno para análise. O recorte feito no final do mês de junho e início de julho foi adotado por tratar-se do período mais frio do ano (ROSSI; KRUGER; BRODE, 2012), próximo ao solstício de inverno. Além disso, a condição de inverno em Curitiba apresenta vantagens em termos de maior probabilidade de períodos de estiagem (invernos, em geral, secos) com amplitude térmica mais acentuada do que em outros períodos do ano.

\section{Local do experimento}

Durante o teste piloto, as duas células-teste e a célula controle foram implantadas no terreno 1 no bairro de Santa Felicidade, Curitiba. Durante o período de medições de inverno em 2017, tal terreno não se apresentou propício ao experimento para a CT2 (enterrada) pois o solo não possuía drenagem eficiente em períodos de chuva, tendo ocorrido a infiltração de água para dentro da célula-teste no teste piloto. Por estes motivos, a $\mathrm{CT}_{2}$ foi relocada para o terreno 2 da mesma rua, que possui melhor drenagem. A célula-teste 1 e a célula controle permaneceram no terreno 1.

A Figura 3 mostra a localização dos terrenos 1 e 2, apresentando uma distância de aproximadamente 150 metros entre o terreno 1, onde permaneceram a CT1 e a CC, e o ponto para onde foi realocada a CT2 no terreno 2 . 


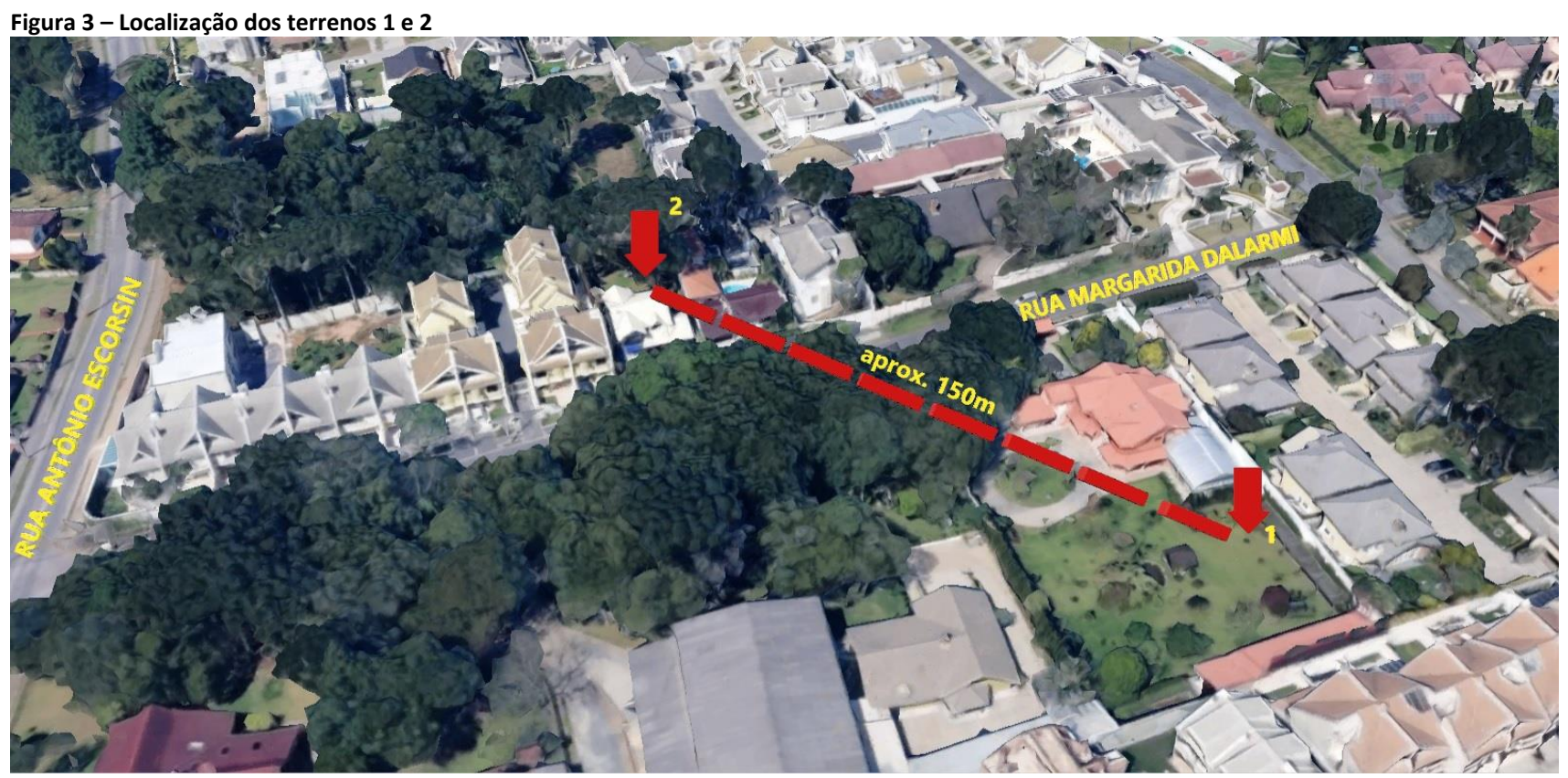

Fonte: Adaptado de Google Earth (2017).

\section{Solo do local do experimento}

A pesquisa de Talamini Neto (2001) realizou a caracterização geotécnica do solo de Curitiba utilizando a integração de 373 boletins de sondagens simples, seis cartas topográficas, 245 georreferenciamentos de poços profundos e pesquisas de campo para levantar aspectos geotécnicos do solo. Após as verificações e correções dos dados e com a implementação de um Sistema de Informações Geográficas (SIG) para a geração de um mapa topográfico simplificado, foram realizadas análises geoestatísticas, interpolações e geração de cartas de isovalores que constituem um modelo geotécnico digital tridimensional que permite a navegação virtual entre unidades geotécnicas. Embora trabalhando com dados interpolados, assumiu-se que o bairro de Santa Felicidade, onde foi locado o experimento do presente estudo, tem seu solo constituído pela Formação Guabirotuba e por solos residuais. O solo da Formação Guabirotuba é composto principalmente por argilas cinzas, sobreadensadas ${ }^{1}$ e fraturadas ${ }^{2}$, e subordinadas por lentes arcosianas ${ }^{3}$, e apresenta condições razoáveis para obras subterrâneas no que condiz à estabilidade e necessidade de suportes, com condições mais adequadas em profundidades superiores a $15 \mathrm{~m}$. Já os solos residuais são constituídos de materiais com diferentes granulometrias, com predomínio de sítios argilosos e arenosos, podendo apresentar estrutura da rocha original, o que os colocam em condições favoráveis para a obras subterrâneas no que condiz à estabilidade e necessidade de suportes. Quanto à profundidade de rocha sã, o território do bairro mostra tanto acessos rasos (o a $15 \mathrm{~m}$ ) quanto acessos profundos (> $30 \mathrm{~m}$ ).

\section{Parâmetros avaliados}

Os parâmetros avaliados para a verificação da eficiência térmica das células foram o somatório de graus-hora para aquecimento, as amplitudes térmicas, os valores absolutos, o fator decremental e os sensores internos de cada célula em dia de céu claro.

A análise de graus-hora para aquecimento é resultado do somatório de graus-hora desconforto por frio, assumindo-se $18{ }^{\circ} \mathrm{C}$ como temperatura de referência. Assim, somente foram somados os valores que estiveram abaixo dos $18^{\circ} \mathrm{C}$. 
A amplitude térmica indica os maiores picos de temperatura diária e, consequentemente, uma menor estabilidade térmica do ambiente avaliado. $O$ cálculo da amplitude térmica é feito a partir da diferença entre a temperatura máxima e a mínima diária.

$A_{D}=T_{\text {máx }}-T_{\text {min }}$

Onde:

$A_{D}$ é a amplitude térmica diária (K);

$T_{\text {máx }}$ é a temperatura máxima diária $\left({ }^{\circ} \mathrm{C}\right)$;

$T_{\text {máx }}$ é a temperatura mínima diária $\left({ }^{\circ} \mathrm{C}\right)$.

A radiação solar é a principal fonte de energia utilizada neste estudo. A maior parte desta é absorvida pela superfície da Terra, aquecendo o solo e impactando indiretamente nas condições locais de temperatura do ar (efeito do albedo). A intensidade que a onda de radiação solar chega à superfície terrestre depende da presença de poluição, nuvens, poeira, entre outros (fatores de depleção atmosférica) (DUFFIE; BECKMAN, 2013). Portanto, em um dia de céu claro, a intensidade de radiação solar será maior quando comparada à de um dia nublado. Conforme o estudo de Peres, Boschi e Souza (2016), a amplitude térmica do ar pode ser utilizada para estimar as radiações global e líquida.

Com base nas informações expostas, esta pesquisa utilizou o cálculo da amplitude térmica diária para a definição do dia de céu claro, considerando que, quanto maior a amplitude diária, maior a intensidade de radiação solar incidente. A definição dos dias de céu claro facilita a comparação dos resultados, dado que as amplitudes térmicas nesses dias costumam ser as mais altas e também devido ao fato de se padronizar assim as análises, com recortes diários de diferentes configurações.

Para a apresentação dos valores absolutos, foram levantadas as temperaturas médias, máximas e mínimas auferidas. A temperatura média $\left({ }^{\circ} \mathrm{C}\right)$ foi definida pela média das temperaturas máximas e mínimas auferidas diariamente durante o período de experimentação. Após este cálculo, apresentou-se a maior média diária calculada para cada período de análise.

O atraso térmico foi calculado pela quantidade de tempo (em horas) a partir do pico de temperatura externa em relação à interna nas células experimentadas.

Para cada sensor posicionado no interior das células foi gerado o recorte de dia de céu claro e realizada a comparação dos diferentes tipos de células testadas (térrea, enterrada e semienterrada), averiguando-se suas amplitudes para verificar o maior desempenho térmico.

A análise do recorte de dia de céu claro também incluiu o fator decremental. Quando uma onda de calor se propaga do ambiente externo para o interior, a amplitude externa sofrerá uma variação que depende das propriedades termofísicas dos materiais do envelope. A razão entre a amplitude interna e a amplitude externa é o que define o fator decremental.

$F D=\frac{A_{\text {Dint }}}{A_{\text {Dext }}}$

Onde:

$F D$ é o fator decremental (adimensional); 
$A_{D_{\text {int }}}$ é a amplitude térmica diária interna (K);

$A_{D_{\text {ext }}}$ é a amplitude térmica diária externa (K).

A partir deste cálculo pode ser determinada a capacidade de armazenamento de calor de uma envoltória. Quanto menor for o fator decremental, melhor será a estabilidade térmica do ambiente interno.

\section{Resultados}

A Figura 4 mostra as temperaturas internas auferidas pelos sensores centrais de cada uma das células e a temperatura do solo do terreno 2 medidas durante o período de monitoramento. Grifada em cinza claro está a faixa de conforto de $18{ }^{\circ} \mathrm{C}$ a $29{ }^{\circ} \mathrm{C}$, estabelecida conforme Givoni (1992).

Figura 4 - Temperaturas internas no período de monitoramento de inverno

TEMPERATURASINTERNAS

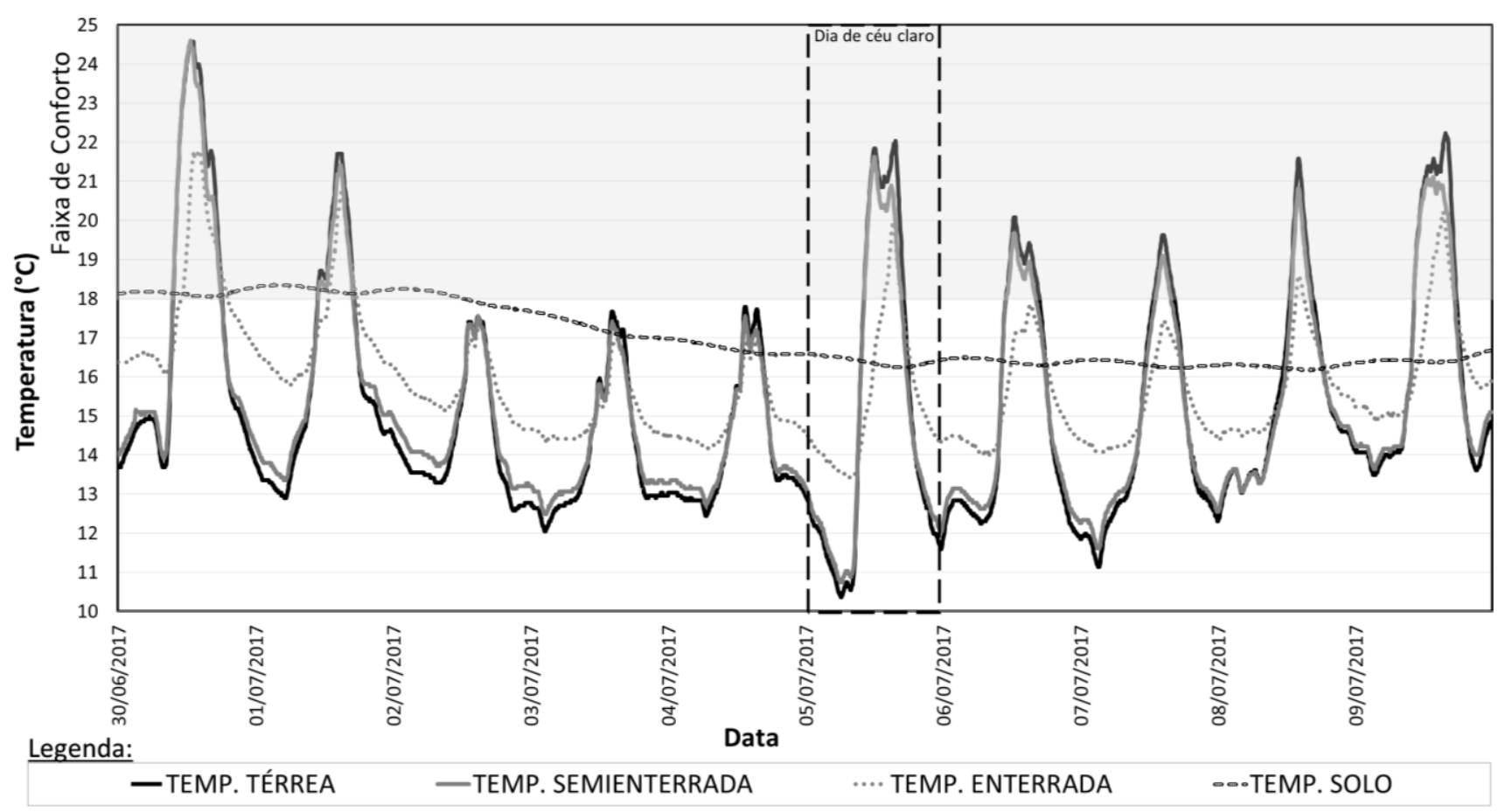

Fonte: Os autores.

É possível verificar na Figura 4 que a célula controle (térrea), seguida da célula-teste 1 (semienterrada), situam-se dentro da faixa de conforto por mais tempo do que a célulateste 2 (enterrada). No entanto, também é visto que conforme as temperaturas baixam bruscamente, as temperaturas internas da CC e da CT1 são as que mais se afastam da faixa de conforto. Tais constatações mostram o efeito significativo do aumento de massa térmica na $\mathrm{CT}_{2}$ e da pouca contribuição do enterramento das duas paredes de CT1 de modo a criar condições de armazenamento térmico distinto da CC.

Considerando que os períodos abaixo da faixa de conforto são prolongados para todas as células, isso significa que a CC e a CT1 dispenderiam mais energia para atingir temperaturas de conforto e mantê-las, e, para tanto, foi realizada a análise de conforto (análise do somatório de graus-hora). 


\section{Análise de graus-hora para aquecimento}

Como forma de interpretar os resultados em termos de conforto/desconforto, adota-se aqui o método do somatório de graus-hora nesta análise. Os resultados mostram os somatórios de graus-hora em desconforto por frio para os dez dias de experimentação, portanto, os totais de graus-hora para aquecimento $\left(\mathrm{Tb}=18^{\circ} \mathrm{C}\right)$ para as três células e para os terrenos 1 e 2, correspondentemente ao ambiente externo (Figura 5). As colunas são apresentadas em ordem decrescente de graus-hora para aquecimento.

Figura 5 - Somatório de graus-hora para aquecimento durante o período de monitoramento de inverno

Somatório de graus-hora para aquecimento - Inverno

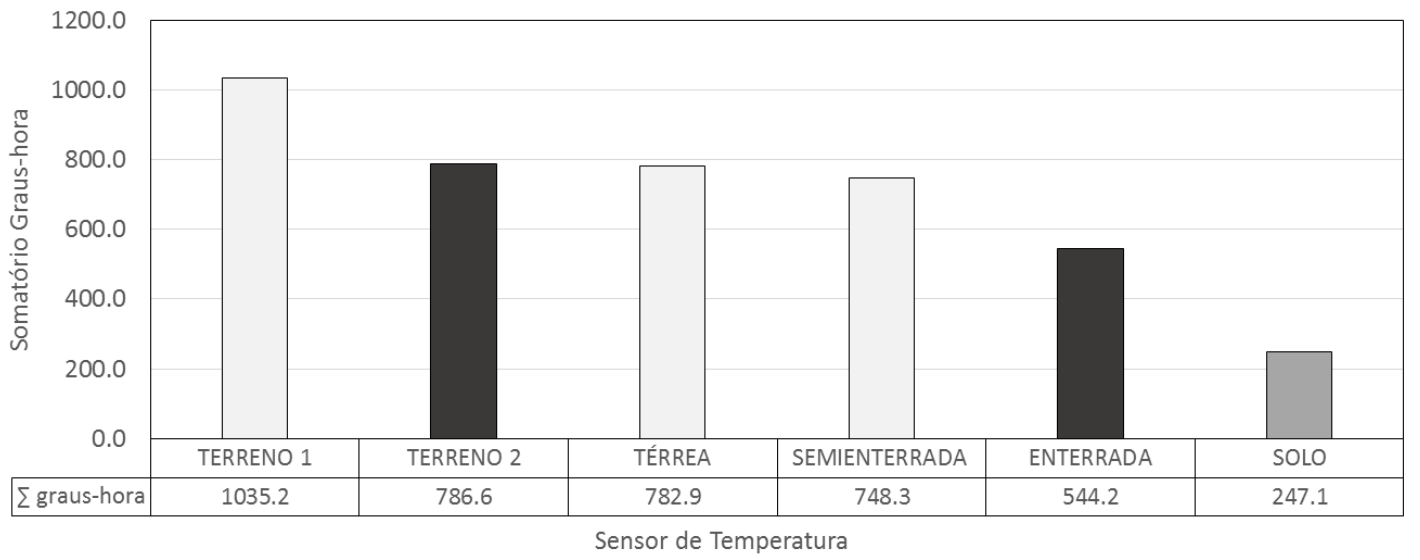

Fonte: Os autores.

As temperaturas externas apresentam os maiores níveis de graus-hora para aquecimento no terreno 1 , onde estiveram implantadas a CC (térrea) e a CT1 (semienterrada). O somatório de graus-hora de aquecimento aponta $1.035,2^{\circ} \mathrm{C}$.h. Já no terreno 2, onde esteve implantada a CT2 (enterrada) foi auferido o somatório de 786,6 ${ }^{\circ} \mathrm{C}$.h de graus-hora para aquecimento. $\mathrm{O}$ menor somatório de graus-hora para aquecimento foi o do sensor que estava no solo, de $247,1^{\circ} \mathrm{C}$.h.

Entretanto, devido às condições do entorno dos dois terrenos, as quais impactaram no microclima, foi necessário considerar o efeito do microclima nessa comparação entre células. No caso particular dos dois locais estudados, a diferença maior foi causada pela maior presença de obstáculos no entorno do terreno 2, com maior quantidade de vegetação ao redor, enquanto que o terreno 1 , junto ao respectivo ponto de medição, apresentava grande abertura de céu e ausência de árvores próximas (conforme Figura 3). Quando as células são correlacionadas com seus respectivos terrenos de locação é possível verificar que o solo apresenta ainda o menor valor para o somatório de graushora para aquecimento. Já quanto às células-teste, a célula controle (térrea) possui o maior somatório de graus-hora para aquecimento, seguida da semienterrada (CT1) e da enterrada ( $\mathrm{CT} 2$ ), porém com menor disparidade relativa.

Os somatórios de graus-hora dos sensores externos locados nos terrenos 1 e 2 foram assumidos como demandas a serem cumpridas e, a partir destas, foi calculada a porcentagem relativa de cada célula relativamente ao seu respectivo terreno de locação durante o período de experimento quanto aos graus-hora para aquecimento. Os resultados são mostrados na Tabela 1. 
BIASI, Juliana Aparecida; KRÜGER, Eduardo Leite.

Estudo do desempenho térmico de células-teste enterrada e semienterrada

\begin{tabular}{|c|c|}
\hline Tipo de célula & Porcentagem relativa de graus-hora para aquecimento \\
\hline Térrea & $75,6 \%$ \\
\hline Semienterrada & $72,3 \%$ \\
\hline Enterrada & $69,2 \%$ \\
\hline
\end{tabular}

No inverno nota-se que a célula controle térrea (75,6\%) é a que mostra o maior somatório de graus-hora para aquecimento quando somados os graus-hora abaixo de $18{ }^{\circ} \mathrm{C}$, seguida da semienterrada $(72,3 \%)$ e pela enterrada $(69,2 \%)$.

Amplitude térmica, valores absolutos e atraso térmico

A Figura 6 mostra a amplitude térmica diária do ambiente externo, das células e do solo auferidas durante o período de medição de inverno. $O$ valor representa a diferença encontrada entre temperatura máxima e mínima diários.

Figura 6 - Amplitude térmica diária do ambiente externo, das células e do solo auferidos durante o período de medição de inverno

\section{Amplitude Térmica Diária}

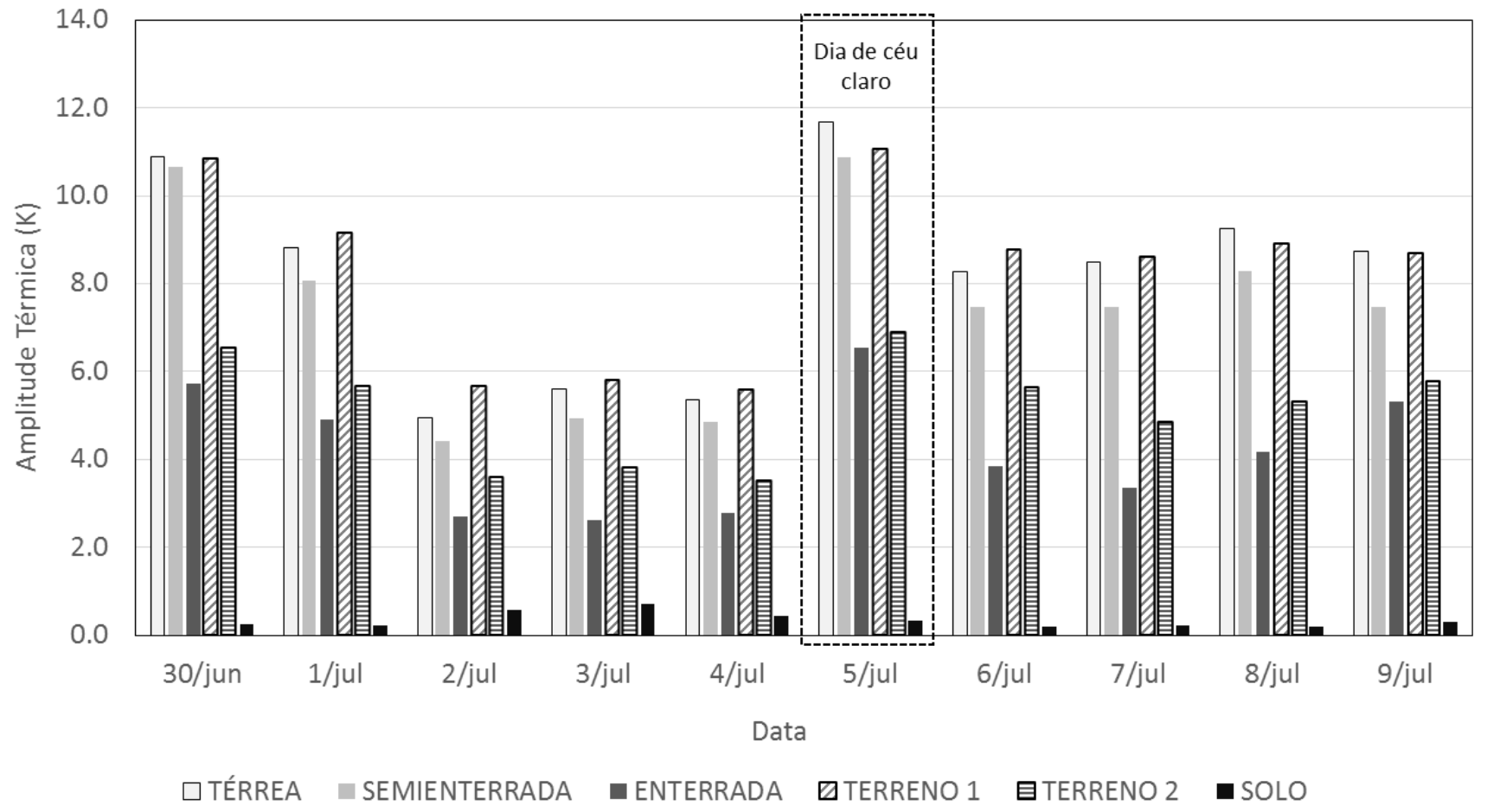

Fonte: Os autores.

É possível identificar que, dentre todos os dias medidos, o dia 05/07 possui as maiores amplitudes térmicas para ambos os terrenos e por este motivo é identificado como dia de céu claro. A Tabela 2 reforça este resultado mostrando as amplitudes diárias de cada célula, dos terrenos e do solo durante o período de experimentação realizado no inverno.

Também se constata que a célula-teste enterrada $(4,2 \mathrm{~K})$ possui em média as menores amplitudes térmicas diárias das células auferidas, seguida da célula-teste semienterrada $(7,5 \mathrm{~K})$ e a célula controle térrea $(8,2 \mathrm{~K})$.

Quanto aos dois locais de experimentação, o terreno 1 possui uma maior amplitude térmica quando comparado ao terreno 2, provavelmente pelo fato da área deste lote ser mais descampada, portanto mais suscetível à variação de quantidade de radiação solar e menos protegida dos ventos dominantes. Levando em consideração o fato de 
que os terrenos não possuem a mesma amplitude térmica e temperaturas externas, os resultados de cada uma das células foram correlacionados às suas respectivas locações, tratados e então comparados entre si.

Tabela 2-Amplitudes diárias em cada tipo de célula durante o período de inverno

\begin{tabular}{ccccccc}
\hline Data & Térrea & Semienterrada & Enterrada & $\begin{array}{c}\text { Externa terreno } \\
\mathbf{1}\end{array}$ & Externa terreno 2 & Solo terreno 2 \\
\hline $\mathbf{3 0 / 0 6}$ & 10,9 & 10,7 & 5,7 & 10,8 & 6,5 & 0,2 \\
\hline $\mathbf{0 1 / 0 7}$ & 8,8 & 8,1 & 4,9 & 9,2 & 5,7 & 0,2 \\
\hline $\mathbf{0 2 / 0 7}$ & 5,0 & 4,4 & 2,7 & 5,7 & 3,6 & 0,6 \\
\hline $\mathbf{0 3 / 0 7}$ & 5,6 & 4,9 & 2,6 & 5,8 & 3,8 & 0,7 \\
\hline $\mathbf{0 4 / 0 7}$ & 5,3 & 4,9 & 2,8 & 5,6 & 3,5 & 0,4 \\
\hline $\mathbf{0 5 / 0 7}$ & 11,7 & 10,9 & 6,5 & 11,1 & 6,9 & 0,3 \\
\hline $\mathbf{0 6 / 0 7}$ & 8,3 & 7,5 & 3,8 & 8,8 & 5,6 & 0,2 \\
\hline $\mathbf{0 7 / 0 7}$ & 8,5 & 7,5 & 3,4 & 8,6 & 4,8 & 0,2 \\
\hline $\mathbf{0 8 / 0 7}$ & 9,3 & 8,3 & 4,2 & 8,9 & 5,3 & 0,2 \\
\hline $\mathbf{0 9 / 0 7}$ & 8,7 & 7,5 & 5,3 & 8,7 & 5,8 & 0,3 \\
\hline MÉDIA & 8,2 & 7,5 & 4,2 & 8,3 & 5,2 & 0,3 \\
\hline
\end{tabular}

Fonte: Os autores.

A fim de realizar uma comparação entre as células, a Tabela 3 mostra os valores absolutos das temperaturas $\left({ }^{\circ} \mathrm{C}\right.$ ) auferidas em cada tipo para $\mathrm{O}$ intervalo de experimentação do inverno.

\begin{tabular}{|c|c|c|c|c|c|}
\hline $\begin{array}{l}\text { VALORES } \\
\text { ABSOLUTOS }\end{array}$ & $\begin{array}{c}T_{\mathrm{cC}} \\
\text { TÉRREA }\end{array}$ & $\begin{array}{c}\mathrm{T}_{\mathrm{CT1} 1} \\
\text { SEMIENTERRADA }\end{array}$ & $\begin{array}{c}T_{\mathrm{CT2} 2} \\
\text { ENTERRADA }\end{array}$ & $\begin{array}{c}\mathrm{T}_{\text {EXT1 }} \\
\text { TERRENO } 1\end{array}$ & $\begin{array}{c}\mathrm{T}_{\text {EXT2 }} \\
\text { TERRENO } 2\end{array}$ \\
\hline Média & 17,0 & 15,1 & 15,8 & 13,8 & 14,7 \\
\hline Máxima & 20,5 & 20,1 & 18,8 & 19,3 & 18,3 \\
\hline Mínima & 12,3 & 12,6 & 14,6 & 11,0 & 13,1 \\
\hline
\end{tabular}

Os resultados da Tabela 3 mostram médias de temperatura mais baixas para a CT1 (semienterrada) e para a $\mathrm{CT}_{2}$ (enterrada), enquanto a CC (térrea) mostra uma média mais alta, com temperatura mínima mais baixa $\left(12,3^{\circ} \mathrm{C}\right)$ e máxima mais alta $\left(20,5^{\circ} \mathrm{C}\right)$. A $\mathrm{CT} 2$ apresentou a temperatura mínima mais alta $\left(14,6^{\circ} \mathrm{C}\right)$ e temperatura máxima mais baixa $\left(18,8{ }^{\circ} \mathrm{C}\right)$. Para um resultado mais acurado, se fez necessário correlacionar as células com suas respectivas locações. A partir disso foi gerado o fator decremental razão entre a amplitude interna sobre a amplitude externa (Figura 7).

O fator decremental representa o grau de amortecimento térmico do ambiente interno quanto às variações térmicas externas, sendo seu valor mais baixo para um maior desempenho nesse quesito. A CT2 (enterrada) apresentou os melhores resultados com os menores valores, exceto no dia 09/07 quando esta é superada pela CT1 (semienterrada). A CT1, por sua vez, nos demais dias ficou em segundo lugar, seguida pela CC (térrea) com os maiores valores. As médias do fator decremental de todos os dias auferidos foram de 0,8 para CT2, 0,9 para CT1 e 1,0 para CC. Ou seja, considerandose a característica básica das células-teste usadas, de baixa transmitância, porém com baixa capacidade térmica, os resultados mostram certa consistência: em CC, o ambiente interno não amortece oscilações térmicas externas, sendo equivalentes as duas amplitudes (valores para fator decremental orbitando em torno de 1 ou $100 \%$ da amplitude externa); em CT1, nota-se uma redução média de 90\% da amplitude externa e em $\mathrm{CT}_{2}$ de $80 \%$ da mesma. Desta forma, o acréscimo de massa térmica com solo local aumentou gradativamente o potencial de amortecimento das células testadas. 


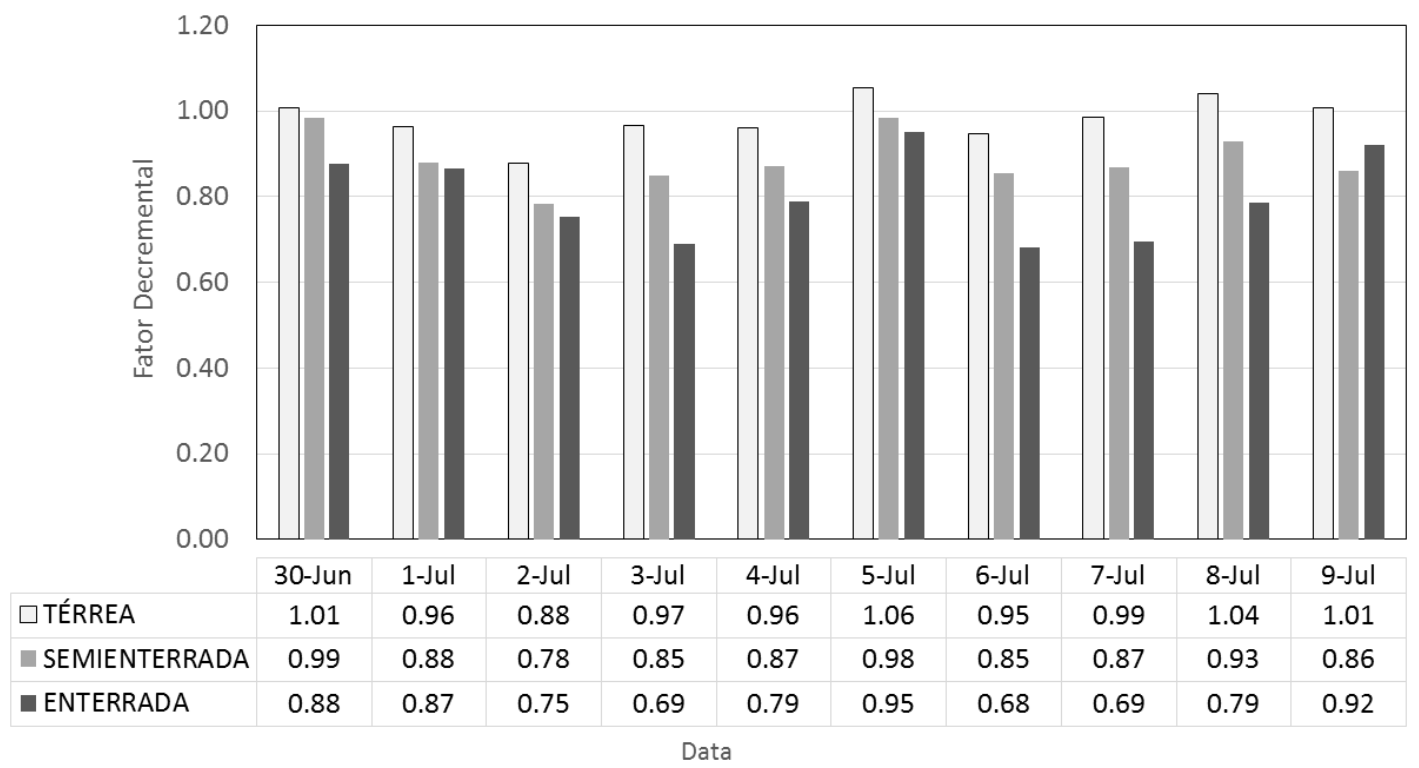

Fonte: Os autores.

Entretanto, o potencial de amortecimento varia conforme as condições do tempo, novamente devido às características termofísicas da envoltória, a qual é bastante suscetível a variações da temperatura externa e respectivas condições de céu. No dia 05 de julho, dia de céu claro, é possível observar que a CC (térrea) mostra o maior fator decremental e que a CT2 (enterrada) apresenta o menor fator. No dia subsequente, ainda beneficiada com o aquecimento acumulado no solo devido ao dia anterior, $\mathrm{CT}_{2}$ mostrou um fator decremental ainda menor (68\%) e mais discrepante de CT1 (85\%) e CC (95\%), sendo este o menor observado no período.

Ao analisar os resultados em conjunto dos gráficos de amplitude térmica e de medição ao longo do período, é possível verificar que a célula-teste enterrada possui menor amplitude e menor afastamento da zona de conforto térmico do que as outras células. Verifica-se portanto que, conforme já exposto no estudo de Bernardos et al. (2014), a célula-teste enterrada necessita de menor demanda energética para manter a temperatura do ar interno em situação de conforto térmico.

Durante o período de monitoramento foram levantadas as temperaturas máximas diárias externas de cada terreno e internas de cada célula-teste a fim de verificar qual seria o atraso térmico diário de cada célula. Os resultados estão apresentados na Tabela 4.

\begin{tabular}{|c|c|c|c|}
\hline DIA & $\begin{array}{c}\text { CC } \\
\text { TÉRREA }\end{array}$ & $\begin{array}{c}\text { CT1 } \\
\text { SEMIENTERRADA }\end{array}$ & $\begin{array}{c}\text { CT2 } \\
\text { ENTERRADA }\end{array}$ \\
\hline $30 /$ jun & 0 & 0 & 2 \\
\hline 01/jul & 0 & 1 & 1 \\
\hline 02/jul & 1 & 1 & 1 \\
\hline 03/jul & 1 & 1 & 2 \\
\hline 04/jul & 0 & 0 & 1 \\
\hline 05/jul & 1 & 0 & 1 \\
\hline 06/jul & 0 & 0 & 1 \\
\hline 07/jul & 0 & 0 & 0 \\
\hline 08/jul & 1 & 1 & 1 \\
\hline 09/jul & 0 & 0 & 0 \\
\hline
\end{tabular}

Fonte: Os autores. 
É possível verificar que a célula-teste enterrada possui o maior atraso térmico e a célula controle térrea o menor, com desempenho intermediário da célula-teste semienterrada.

Temperatura de superfície no piso em dia de céu claro

A Figura 8 apresenta as amostras de temperaturas dos sensores superficiais locados, em cada célula, no centro da área do piso e a temperatura do solo (terreno 2 ) em dia de céu claro (05/07/2017) e destaca a maior e a menor diferença de amplitude entre as células comparadas: CC (célula controle) e CT2 (célula-teste 2 - enterrada).

Figura 8 - Temperaturas superficiais de piso em dia de céu claro durante o período de inverno

Dia de Céu Claro - Temperatura do Sensor Superficial

Piso

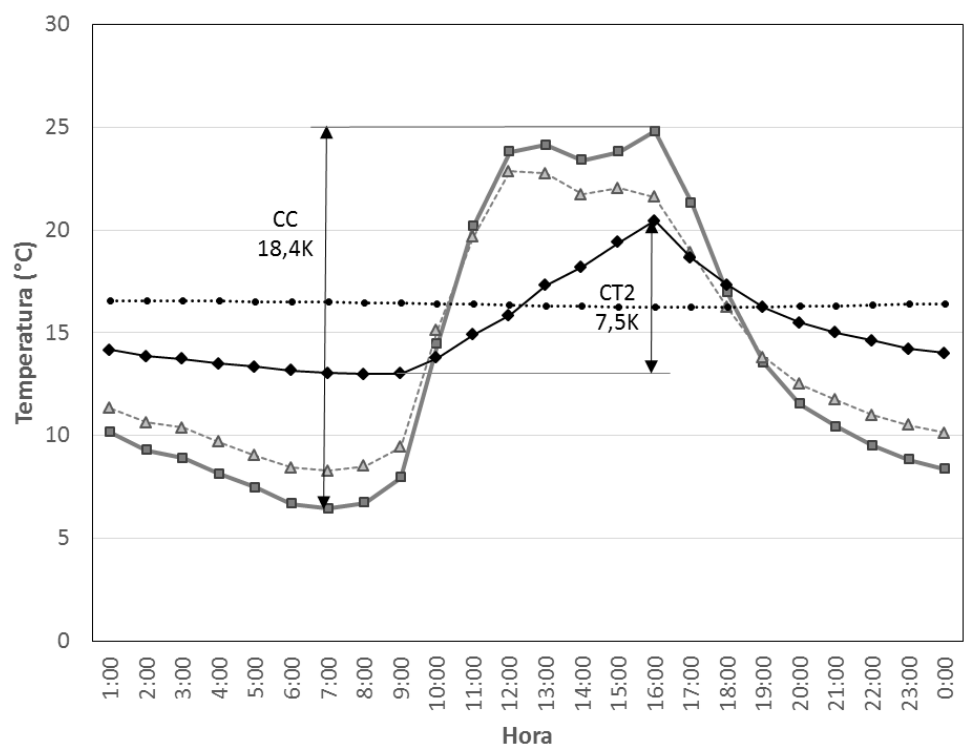

Legenda:

Fonte: Os autores.

Nos sensores de piso verifica-se que a maior diferença de amplitude térmica diária ocorre na célula controle (térrea) com 18,4 K auferidos. A célula-teste 2 (enterrada) apresentou uma amplitude térmica de apenas 7,4 K, enquanto a célula-teste 1 (semienterrada) apresentou 14,5 K. Verificam-se, na comparação com a temperatura do ar interna, maiores diferenças entre as células-teste e a célula controle, sendo a $\mathrm{CT}_{2}$ (enterrada) a que apresentou maior estabilidade e amplitude mais baixa. $O$ fator decremental, recalculado agora a partir da amplitude interna auferida no sensor superficial locado no piso e no sensor do ambiente interno de cada célula, é representado no gráfico para o dia de céu claro e comparado com o fator decremental calculado a partir da temperatura do ar (Figura 9).

Mantém-se a ordem observada anteriormente, porém com maior disparidade no caso do sensor de temperatura superficial. O menor valor de fator decremental tanto para o sensor de piso quanto para a temperatura ambiente foi apresentado pela $\mathrm{CT}_{2}$ (enterrada) seguida da CT1 (semienterrada). 
Figura 9 - Fator decremental em dia de céu claro

Fator Decremental - Inverno

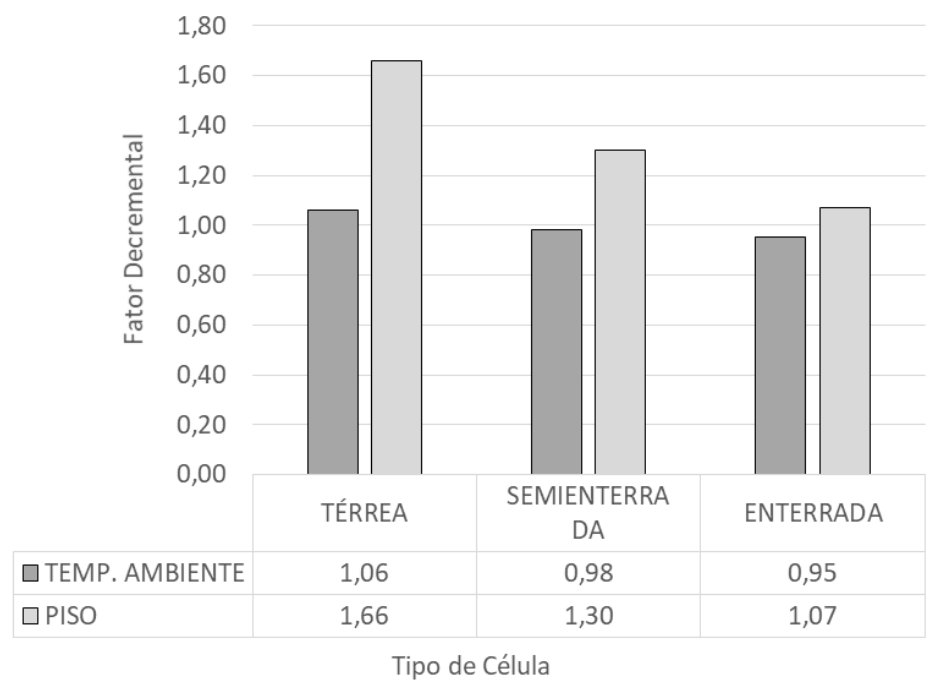

Fonte: Os autores.

\section{Conclusão}

A partir dos resultados deste estudo para o período do inverno, os quais apresentaram grandes somatórios de graus-hora para aquecimento, pode-se confirmar o que diz a NBR 15220 (ABNT, 2005) e o estudo de Alves e Schmid (2015), que o condicionamento passivo para a zona bioclimática 1 do Brasil, onde está situada a cidade de Curitiba, será insuficiente para manter os níveis de conforto térmico durante os períodos mais frios. Salienta-se, porém, que a utilização de método passivo que utilize a massa térmica do solo, tal como a célula-teste enterrada, pode ser aplicado para reduzir os gastos com energia de forma a manter o ambiente termicamente mais estável durante o período mais frio do ano, o qual, conforme Alves e Schmid (2015), representa a maior demanda da zona bioclimática 1 .

O estudo conclui que a célula-teste enterrada apresenta melhor desempenho térmico em termos de amortecimento térmico e redução do frio quando comparada a uma célula controle térrea durante o período de inverno na cidade de Curitiba - PR. Em sequência, a célula semienterrada também se demonstrou mais eficiente que a célula controle térrea. Com este dado, conclui-se também que, como já argumentado por Anselm (2008), quanto maior a área de contato do invólucro com o solo, maior é a eficiência térmica da célula.

A pesquisa apresentou algumas limitações, como o fato do modelo ser em escala (maiores profundidades do solo poderiam ter comportamentos realçados) e de não haver cargas internas por ser uma célula-teste, de modo que estudos em uma edificação real poderiam trazer diferenças no comportamento observado.

Outras limitações referem-se às infiltrações de água ocorridas na célula-teste enterrada advinda da drenagem do subsolo do terreno 1, tendo que ser relocada para o terreno 2. Este fato levou a uma maior complexidade na leitura e tratamento dos resultados, pois as três células não estiveram expostas às mesmas oscilações das variáveis externas. Estudos futuros devem prever um estudo prévio de lençóis freáticos existentes no terreno e da capacidade drenante do solo, previamente à implantação de células ou edificações teste. 
BIASI, Juliana Aparecida; KRÜGER, Eduardo Leite.

Estudo do desempenho térmico de células-teste enterrada e semienterrada

\section{Notas}

(1) Indicação de que o solo esteve, no passado, sujeito a uma tensão superior à atual.

(2) As estruturas produzidas na zona de fratura são as fraturas, falhas e fendas.

(3) Rocha sedimentar arenítica com mais de $25 \%$ de feldspato, muito quartzo e alguns fragmentos de rocha, cores róseas a cinzas.

\section{Referências}

ABNT - ASSOCIAÇÃO BRASILEIRA DE NORMAS TÉCNICAS. NBR 15220 - Desempenho Térmico de Edificações. Rio de Janeiro; 2005.

ALKAFF S. A. et al. A Review of Underground Building towards Thermal Energy Efficiency and Sustainable Development. Renewable and Sustainable Energy Reviews, v. 60, p. 692-713. 2016.

DOI:https://doi.org/10.1016/j.rser.2015.12.085.

ALVES, A. B. M.; SCHMID, A. L. Cooling and Heating Potential of Underground Soil According to Depth and Soil Surface Treatment in the Brazilian Climatic Regions. Energy and Buildings, v. 90, p. 41-50. 2015.

DOI:https://doi.org/10.1016/j.enbuild.2014.12.025.

ANSELM, A. J. Earth Shelters: a review of energy conservation properties in earth sheltered housing. Energy Conservation, v. 31, p.125-48. 2012. DOI:http://dx.doi.org/10.5772/51873

ANSELM, A. J. Passive Annual Heat Storage Principles in Earth Sheltered Housing, a Supplementary Energy Saving System in Residential Housing. Energy and Buildings, v. 40, p. 1214-1219. 2008.

DOI:https://doi.org/10.1016/j.enbuild.2007.11.002.

BENARDOS, A. et al. Modern Earth Sheltered Constructions: a paradigm of green engineering. Tunneling and Underground Space Technology, v. 41, p. 46-52. 2014. DOI:https://doi.org/10.1016/j.tust.2013.11.008.

CHMYZ, I. et al. A Arqueologia da Área do Aterro Sanitário da Região Metropolitana de Curitiba, em Mandirituba, Paraná. Curitiba: CEPA, 2003.

DERRADJI, M.; AICHE, M. Modeling the soil surface temperature for natural cooling of buildings in hot climates. Procedia Computer Science, v. 32, p. 615-621. 2014. DOI:https://doi.org/10.1016/j.procs.2014.05.468.

DUFFIE, J. A.; BECKMAN, W. A.; WOREK, W. M. Solar engineering of thermal processes. New York: Wiley, 2013.

FERNANDES, L. C.; KRÜGER, E. L. Thermal Performance of a Thermal Performance of a Roof-Pond System under Subtropical Conditions. In: INTERNATIONAL CONFERENCE ON PASSIVE AND LOW ENERGY ARCHITECTURE (PLEA): DESIGN TO TRIVE, 33, 2017, Edinburgh. Proceedings [...]. Edinburgh: PLEA, 2017. v. 3, p. 4039-4045.

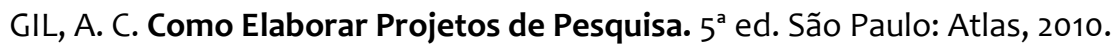

GIVONI, B. Performance and Applicability of Passive and Low-Energy Cooling Systems. Energy and Buildings, v. 17, p. 177-199. 1991. DOI:https://doi.org/10.1016/0378-7788(91)90106-D.

GIVONI, B. Comfort Climate Analysis and Building Design Guidelines. Energy and Buildings, v. 18 (1), p. 11-23. 1992. DOI:https://doi.org/10.1016/0378-7788(92)90047-K.

HAIT, J. Passive Annual Heat Storage: improving the design of earth shelters. 3... ed. Chino Valley: Rocky Mountain Research Center, 2013. 
KOTTEK, M.; J. GRIESER, C. BECK; B. RUDOLF; F. RUBEL. World map of the Köppen-Geiger climate classification updated. Meteorologische Zeitschrift, v. 15, p. 259-263. jun. 2006. DOI: https://doi.org/10.1127/0941-2948/2006/0130.

KRÜGER, E. L.; LANGE, S. C.; FERNANDES, L.; ROSSI, F. Avaliação do potencial de resfriamento de um sistema tetoreservatório para condições subtropicais. Ambiente Construído, Porto Alegre, v. 16, n. 3, p. 107-125, jul./set. 2016. DOI:http://dx.doi.org/10.1590/s1678-86212016000300095.

LAMBERTS, R.; DUTRA, L.; PEREIRA, F.O.R. Eficiência Energética na Arquitetura. 3.ed. Rio de Janeiro, 2014.

PERES, J. G.; BOSCHI, R. S.; SOUZA, C. F. Avaliação de modelos agrometeorológicos que utilizam a amplitude térmica do ar atmosférico para a estimativa das radiações global e líquida. Revista Brasileira de Agricultura Irrigada, v. 10, n. 4, Fortaleza, p. 715 - 725, Jul - Ago, 2016. DOI:https://doi.org/10.7127/RBAI.V10N400344.

ROSSI, Francine Aidie; KRUGER, Eduardo Leite; BRODE, Peter. Definição de faixas de conforto e desconforto térmico para espaços abertos em Curitiba, PR, com o índice UTCI. Ambient. constr., Porto Alegre, v. 12, n. 1, p. 41-59, mar. 2012. DOI:http://dx.doi.org/10.1590/S1678-86212012000100004.

STANIEC, M.; NOWAK, H. Analysis of the Earth-Sheltered Buildings' Heating and Cooling Energy Demand Depending on Type of Soil. Archives of Civil and Mechanical Engineering, v. 11, n. 1, p. 221-235. 2011.

DOI:https://doi.org/10.1016/S1644-9665(12)60185-X.

TALAMINI NETO, E. Caracterização Geotécnica do Subsolo de Curitiba para o Planejamento de Ocupação do Espaço Subterrâneo. 2001. 223 f. Dissertação (Mestrado em Geotecnia) - Escola de Engenharia de São Carlos, Universidade de São Paulo, São Carlos, 2001.

WEIMER, Günter. Arquitetura Popular Brasileira. São Paulo: Martins Fontes, 2005.

WEIMER, Günter. Arquitetura indígena brasileira: suas origens remotas. In: FERREIRA, Mario dos Santos; BREGATTO, Paulo Ricardo; KOTHER, Maria Beatriz (Org.). Arquitetura \& Urbanismo: Posturas, Tendências e Reflexões. Porto Alegre: Livraria do Arquiteto, 2008. v. 1, p. 27-46.

\section{Juliana Aparecida Biasi}

Arquiteta e Urbanista (PUCPR). Mestre em Engenharia Civil (UTFPR). Professora de Graduação em Arquitetura e Urbanismo na Universidade do Oeste de Santa Catarina. Endereço postal: Unoesc / Campus Videira / Departamento de Arquitetura e Urbanismo, Rua Paese, 198, Videira, SC, CEP 89566-252

\section{Eduardo Leite Krüger}

Engenheiro Civil. Doutor em Arquitetura (Hannover, Alemanha). Professor Associado IV da Universidade Tecnológica Federal do Paraná (UTFPR), professor do Departamento de Construção Civil e do Programa de PósGraduação em Engenharia Civil. Endereço postal: UTFPR / Campus Curitiba / Sede Ecoville, Rua Deputado Heitor Alencar Furtado, 4900, Curitiba, PR, CEP 81280-340 